\title{
Effect of Physician Participation in a Multi-element Health Information and Data Exchange Program on Chronic Illness Medication Adherence
}

\author{
Samantha F. De Leon, PhD, Lucas Pauls, MPA, Vibhuti Arya, PharmD, \\ Sarah C. Shih, MPH, Jesse Singer, DO, and Jason J. Wang, PhD
}

Background: The Primary Care Information Project (PCIP) includes a network of more than 10,000 physicians across New York City focusing on improving the quality of patient care through the use of health information technology and data exchange.

Methods: We assessed adherence, defined as the percentage with a medication possession ratio (MPR) $\geq \mathbf{8 0} \%$, across 2 time periods for union members whose primary care providers participated in the PCIP compared with those whose providers did not participate. Using prescription claims data from 2008 and 2011, the MPR was calculated for disease-specific categories of drugs among patients with diabetes, hypertension, and both conditions.

Results: Greater improvements in the number of adherent members were observed for the PCIP patients with diabetes who were taking diabetes-specific medications (odds ratio [OR], 2.03; 95\% confidence interval [CI], 1.08-3.83 for PCIP, versus OR, 1.14; 95\% CI, 0.81-1.60 for non-PCIP) and patients with diabetes who are taking lipid-controlling medications (OR, 1.64; 95\% CI, 0.73-3.65 for PCIP versus 0R, 0.85; 95\% CI, 0.55-1.32 for non-PCIP). However, the magnitude and significance of these associations were diminished when practices providing reduced prescription co-pays were excluded from the analyses.

Conclusion: Access to primary care providers participating in a public health initiative was associated with some improvement in medication adherence. However, reducing prescription co-pays may be a stronger factor for higher medication adherence among union members. (J Am Board Fam Med 2015; 28:742-749.)

Keywords: Drug Utilization, Health Promotion, Primary Health Care, Public Health, Electronic Medical Records

As the chronic disease burden continues to grow among the US population, ${ }^{1-4}$ primary care doctors will be expected to successfully manage and treat a greater proportion of patients with $\geq 1$ chronic con-

This article was externally peer reviewed.

Submitted 7 January 2015; revised 8 May 2015; accepted 18 May 2015.

From the New York City Department of Health \& Mental Hygiene, Primary Care Information Project (PCIP), Long Island City, NY (SFDL, SCS, JS, JJW); the 32 BJ Health Fund, New York, NY (LP); and the Clinical Pharmacy Practice, St. John's University, Queens, NY (VA). levy.

Funding: This research was funded by New York City tax

Conflict of interest: none declared.

Corresponding author: Samantha F. De Leon, PhD, New York City Department of Health \& Mental Hygiene, Primary Care Information Project, 2 Gotham Center, 41-09 28th St, CN-52, Queens, NY 11101 (E-mail: sdeleon@health.nyc.gov). dition, such as diabetes, hypertension, and hyperlipidemia. ${ }^{5,6}$ Patient adherence to medication regimens is a key component of effective chronic disease management, yet medication adherence for these conditions tends to be low in the United States. ${ }^{7-10}$ Failure of patients to adhere to medication regimens can lead to adverse health outcomes, such as worsening of chronic conditions, ${ }^{11,12}$ preventable hospitalizations, ${ }^{13,14}$ and death, ${ }^{15-17}$ as well as potentially increasing health care costs. ${ }^{13,18-20}$

Several primary care practice models have been hypothesized to improve health outcomes for patients with chronic conditions-this includes the adoption of an electronic health record (EHR) as a means to assess a practice's patient population and proactively intervene (eg, care coordination for and management of high-risk populations). Payment 
reform and federal incentive programs have also encouraged the adoption of EHRs. Meaningful use (MU) incentives promote the use of registry functions and templates within an EHR to identify, track, and intervene with patients with elevated blood pressure or blood glucose to lower their risk of stroke and heart disease. However, implementing an EHR is not enough. Achieving recognition as a patient-centered medical home (PCMH) potentially improves care coordination and communication, resulting in better health outcomes. ${ }^{21-23}$ In addition, reducing patient barriers to accessing health care and medications has been shown to improve health outcomes. ${ }^{24-26}$ The labor union considered in this study included in its benefits design a steep reduction of prescription co-pay for members accessing practices recognized as PCMHs to facilitate access to medications prescribed for chronic conditions.

The Primary Care Information Project (PCIP), a bureau within the New York City Department of Health \& Mental Hygiene, works with primary care providers to improve population health and reduce health disparities through the use of health information systems and quality improvement activities. ${ }^{27,28}$ Providers participating in PCIP programs receive assistance with implementing an EHR with features such as e-prescribing, provider reminders, and a built-in clinical decision support system based on the Take Care New York guidelines, ${ }^{29}$ which promote the utilization of preventive services in the management and treatment of major chronic conditions such as diabetes, hypertension, and hyperlipidemia — conditions that share risk factors for all-cause mortality. ${ }^{30}$

PCIP collaborated with a payer to assess whether provider participation in the PCIP programs was associated with increased medication adherence for classes of drugs used in the management and treatment of diabetes and hypertension.

\section{Methods}

\section{The Primary Care Information Project}

Established in 2005, PCIP offers primary care providers access to online resources, classes, seminars, and newsletters on important quality improvement and health information technology topics on a quarterly basis. Providers receive assistance to meet MU standards, including onsite consulting by clinical quality improvement specialists to make assess- ments and give feedback to providers on changes needed to redesign workflows to meet MU standards; in-person seminars and webinars to educate providers on $\mathrm{MU}$; and online resource libraries and self-help tools. Providers receive assistance in obtaining recognition as a PCMH from the National Committee for Quality Assurance through indepth, in-person seminars and webinars, as well as ongoing call support and on-site visits by quality improvement specialists to help providers throughout the process.

\section{Study Population}

Prescription claims data from 2008 to 2011 for adult members of the 32BJ Union were available for this study through the 32BJ Health Fund, which manages the health benefits for about 64,000 members working in building services in New York City, mainly as doormen, porters, and maintenance workers, in a variety of locations such as residential buildings, commercial office, and schools. The median household income of members is $\$ 35,000,{ }^{31}$ and roughly half are immigrants for whom English is not their first language. ${ }^{32}$

The prescription drug benefit provided through the union is a comprehensive, closed formulary plan with a mandated generic requirement. The plan was $100 \%$ employer-paid outside of $\$ 7$ and $\$ 22$ co-pays for a 30-day supply of generic or brand drugs, respectively. When filling a prescription through mail order, the co-pays were less expensive: $\$ 14$ and $\$ 44$ for a 90 -day supply. Members are generally required to get their maintenance drugs through mail order after the second fill.

Using the provider specialty field in the claims data, primary care providers were defined as those whose specialties included family practice, geriatrics, general practice, internal medicine, obstetrics and gynecology, and preventive medicine. By cross-referencing National Provider Identifier numbers in the claims data with the PCIP contact management database, 1,243 PCIP primary care providers were identified in the claims data; the remaining 2,839 primary care providers were classified as non-PCIP providers. All physician office location zip codes were restricted to New York City.

Union members who received $100 \%$ of their outpatient primary care visits with any provider enrolled in PCIP, which could be a single provider or multiple providers at different practices, were 
attributed to the PCIP group. Union members were attributed to the non-PCIP group if $100 \%$ of their primary care visits were with any single provider or multiple providers at different practices not enrolled in PCIP. Using this rule, about 4,477 union members were assigned to the PCIP group and about 15,608 union members were assigned to the non-PCIP group. This left 10,652 unassigned members who had primary care visits with both PCIP and non-PCIP providers. These individuals were excluded to avoid assessing a partial effect of the program.

Three chronic disease categories were considered for our study: (1) diabetes only, defined by International Classification of Diseases, Ninth Revision, Clinical Modification codes 250.xx; (2) hypertension only, defined by International Classification of Diseases, Ninth Revision, Clinical Modification codes 401.xx through 405.xx; and (3) diabetes and hypertension together, which was used to consider patients who were sicker or taking a larger number of medications. To be included in the analyses, members had to have a diagnosis of diabetes only, hypertension only, or both conditions throughout the study period (2008-2011).

\section{Medication Possession Ratio}

The medication possession ratio (MPR) is a widely accepted method of measuring medication availability $^{33}$ or the refilling of prescriptions as scheduled so that patients have an adequate supply at hand to take medication(s) as prescribed. The MPR is defined as the sum of the days of prescription supply dispensed between the first and last pharmacy fill (with the last fill excluded), divided by the number of days between the prescriptions. ${ }^{33}$

For each patient, the yearly MPR was tabulated and averaged across each therapeutic drug class to estimate the overall adherence to medication regimens for antidiabetic agents (biguanides, sulfonylureas, thiazolidinediones, insulins, dipeptidyl peptidase IV inhibitors); antihypertensive agents (angiotensin-converting enzyme inhibitors, angiotensin II receptor antagonists, $\beta$-adrenergic blocking agents, calcium channel blocking agents [dihydropyridines], phosphodiesterase inhibitors, thiazide diruetics); and hyperlipidemia agents (HMG-coenzyme A reductase inhibitors, fibric acid derivatives). Drugs within a therapeutic drug class were considered interchangeable; no effort was made to determine whether drugs were switched within a given drug class.

MPRs $>100 \%$ were truncated to $100 \%$ to avoid skewing the results. Values $>100 \%$ can occur for a variety of reasons, including the early refill of prescriptions, the overuse of medication, multiple medications dispensed to achieve a specific dose, or the prescription of combination therapies. ${ }^{8}$

\section{Statistical Analyses}

Average MPRs were generated for calendar year 2008 and compared with calendar year 2011. At baseline, in 2008, fewer of the PCIP providers were live on the EHR compared with 2011, when all PCIP providers included in this study were live on the EHR. Members were considered adherent if the average MPR was $\geq 80 \%$, in line with many studies that have used MPR as an outcome. ${ }^{33} \mathrm{Lo}-$ gistic regression analysis was used to model the proportion of members with MPRs $\geq 80 \%$, adjusted for member characteristics including age, sex, comorbidity status, and primary care provider participation in the PCIP. $P$ values $<.05$ were considered statistically significant. All analyses were conducted using SAS statistical software, version 9.2 (SAS Institute, Cary, NC). This study was reviewed and approved by the institutional review board of the New York City Department of Health \& Mental Hygiene as research on individual or group characteristics or behavior (institutional review board no. 10-085).

\section{Results}

During the study period, $75 \%$ of the PCIP primary care providers were at practices that had on-site visits with PCIP quality improvement specialists, of whom $60 \%$ had $\geq 2$ visits during the study period and $87 \%$ had on-site visits or calls/webinars.

Overall, there were small but significant differences (in terms of age, sex, and number of medications and prescriptions filled at baseline) among members whose primary care providers either participated or did not participate in the PCIP, with the exception that the non-PCIP group did have a higher proportion of members with hypertension (Table 1). Excluded members, who received care from both PCIP and non-PCIP providers, were more similar to the non-PCIP group in terms of proportion of members with diabetes and hypertension, although they had fewer male patients than 


\begin{tabular}{|c|c|c|c|}
\hline & $\begin{array}{l}\text { Non-PCIP } \\
(\mathrm{n}=15,608)\end{array}$ & $\begin{array}{c}\text { PCIP } \\
(\mathrm{n}=4,477)\end{array}$ & $\begin{array}{l}\text { PCIP and Non-PCIP } \\
\text { (Excluded)* }(\mathrm{n}=10,652)\end{array}$ \\
\hline \multicolumn{4}{|l|}{ Member demographics $\dagger$} \\
\hline Mean age (years), mean (SD) & $50.29(10.95)$ & $49.20(10.99)$ & $50.46(10.52)$ \\
\hline Male sex, \% & 82.70 & 90.02 & 71.48 \\
\hline Diabetes (any diagnosis), \% & 23.86 & 19.32 & 24.44 \\
\hline Hypertension (any diagnosis), \% & 58.07 & 47.26 & 57.97 \\
\hline Diabetes and hypertension (any diagnosis), \% & 20.03 & 15.66 & 20.59 \\
\hline \multicolumn{4}{|l|}{ Member prescription patterns } \\
\hline Diabetes-related prescriptions & $\mathrm{n}=1,661$ & $\mathrm{n}=451$ & $\mathrm{n}=1,149$ \\
\hline Medicationsł & 1.72 & 1.73 & 1.74 \\
\hline Prescriptions filled $\$$ & 5.98 & 6.38 & 6.20 \\
\hline Hypertension-related prescriptions & $\mathrm{n}=5,460$ & $\mathrm{n}=1,439$ & $\mathrm{n}=3,519$ \\
\hline Medications†‡ & 1.29 & 1.34 & 1.32 \\
\hline Prescriptions filled\$ & 5.89 & 6.23 & 5.85 \\
\hline Lipid-controlling prescriptions & $\mathrm{n}=3,922$ & $\mathrm{n}=916$ & $\mathrm{n}=2,453$ \\
\hline Medicationsł & 1.17 & 1.16 & 1.18 \\
\hline Prescriptions filled $+\$$ & 3.27 & 3.34 & 3.14 \\
\hline
\end{tabular}

*Union members who had outpatient primary care visits with both Primary Care Information Project (PCIP) and non-PCIP providers were excluded from the analyses.

$+P$ value $<.05$.

$\ddagger$ Medications refers to the total number of unique medications (unique therapeutic drug classes) for which a member has filled prescriptions.

$\S$ Prescriptions filled refers to the total number of prescription claims that were filled by the member.

$\mathrm{SD}$, standard deviation.

either group and were not similar to either group across all prescription behaviors considered.

At baseline, in 2008, MPRs were lower for the PCIP group compared with the non-PCIP group; the largest differences were observed for members with diabetes and no comorbid hypertension (Table 2). Among members with both diabetes and hypertension, across medication categories and PCIP status, the proportion of adherent patients (MPR $\geq 80 \%)$ at baseline was generally higher compared with those with a single condition. Regardless of PCIP status, the proportion of adherent members was lower for lipid-controlling medications across conditions.

Logistic regression results adjusted by age, sex, and primary care provider participation in PCIP differed by chronic condition (Table 3). Among members with diabetes only taking diabetes-specific medications, the PCIP group had greater odds of being adherent, with an MPR meeting or exceeding the $80 \%$ threshold in 2011 (odds ratio [OR], 2.03; 95\% confidence interval [CI], 1.08$3.83)$, compared with the non-PCIP group (OR, 1.14; 95\% CI, 0.81-1.60). Although nonsignificant, a similar pattern was observed among members with diabetes only receiving lipid-controlling medications (OR, 1.64; 95\% CI, 0.73-3.65 for PCIP vs OR, 0.85 ; $95 \%$ CI $0.55-1.32$ for non-PCIP), as well as members with diabetes and hypertension taking diabetes-specific medications or on lipidcontrolling medications. Both the PCIP and nonPCIP groups showed improvements in MPR among members with hypertension only receiving hypertension-specific medications. The PCIP group was less likely to be adherent (MPR $\geq 80 \%$ ) in 2011 compared with the non-PCIP group when considering members with hypertension only taking lipid-controlling medications and members with hypertension and diabetes taking hypertension-specific medications.

During the study period, the 32BJ Health Fund was engaged in a campaign to promote $\mathrm{PCMH}$ to members with chronic conditions. As an incentive, members with chronic conditions who used 2 $\mathrm{PCMH}$ practices participating in the pilot were given a steep reduction in prescription co-pays, corresponding to $\$ 5$ for all 30 -day prescriptions and $\$ 10$ for all 90 -day mail order prescriptions, regardless of generic/brand classification. When the $2 \mathrm{PCMH}$ practices ( 1 each in the PCIP and 
Table 2. Proportion of Medication-Adherent Union Members, from Baseline to the End of the Study, by Primary Care Provider Participation in the Primary Care Information Project

\begin{tabular}{|c|c|c|c|c|c|}
\hline \multirow[b]{2}{*}{ Medication Type } & \multirow[b]{2}{*}{ Patients (n) } & \multicolumn{2}{|r|}{ Baseline } & \multirow{2}{*}{$\begin{array}{c}\text { Adherent Members } \\
\text { at the End of } \\
\text { the Study }(\%) *\end{array}$} & \multirow{2}{*}{$\begin{array}{c}\text { Change (End } \\
\text { of Study - } \\
\text { Baseline) } \dagger\end{array}$} \\
\hline & & MPR (\%) & Adherent Members (\%)* & & \\
\hline \multicolumn{6}{|l|}{ Diabetes (only) } \\
\hline \multicolumn{6}{|c|}{ Diabetes-specific $\neq$} \\
\hline Non-PCIP & 205 & 79.01 & 26.07 & 27.94 & +1.87 \\
\hline PCIP & 63 & 69.70 & 18.52 & 31.76 & +13.24 \\
\hline \multicolumn{6}{|c|}{ Lipid-controlling $\$$} \\
\hline Non-PCIP & 129 & 76.67 & 16.63 & 13.24 & -3.39 \\
\hline PCIP & 40 & 65.32 & 11.11 & 16.47 & +5.36 \\
\hline \multicolumn{6}{|l|}{ Hypertension (only) } \\
\hline \multicolumn{6}{|c|}{ Hypertension-specific $\dagger$} \\
\hline Non-PCIP & 2652 & 79.37 & 33.75 & 37.88 & +4.13 \\
\hline PCIP & 735 & 77.61 & 32.89 & 37.25 & +4.36 \\
\hline \multicolumn{6}{|c|}{ Lipid-controlling $\$$} \\
\hline Non-PCIP & 1198 & 77.63 & 14.59 & 17.05 & +2.46 \\
\hline PCIP & 295 & 76.47 & 12.62 & 13.51 & +0.89 \\
\hline \multicolumn{6}{|c|}{ Comorbid diabetes and hypertension } \\
\hline \multicolumn{6}{|c|}{ Diabetes-specific $\neq$} \\
\hline Non-PCIP & 1322 & 79.67 & 37.37 & 37.87 & +0.50 \\
\hline PCIP & 357 & 76.63 & 36.04 & 37.10 & +1.06 \\
\hline \multicolumn{6}{|c|}{ Hypertension-specific $\|$} \\
\hline Non-PCIP & 1533 & 79.52 & 44.44 & 47.76 & +3.32 \\
\hline PCIP & 390 & 77.39 & 40.57 & 41.94 & +1.37 \\
\hline \multicolumn{6}{|c|}{ Lipid-controlling $\$$} \\
\hline Non-PCIP & 1045 & 78.55 & 29.25 & 31.29 & +2.04 \\
\hline PCIP & 250 & 75.46 & 24.34 & 28.23 & +3.89 \\
\hline
\end{tabular}

$*$ The proportion of members with a medication possession ratio (MPR) $\geq 80 \%$.

†Change in the proportion of members with an MPR $\geq 80 \%$ from baseline (2008) to the end of the study (2011).

$\ddagger$ Diabetes therapeutic drug classes include biguanides, sulfonylureas, thiazolidinediones, insulins, and dipeptidyl peptidase IV inhibitors.

\$Lipid-controlling therapeutic drug classes include HMG-CoA reductase inhibitors and fibric acid derivatives.

|Hypertension therapeutic drug classes include angiotensin-converting enzyme inhibitors, angiotensin II receptor antagonists, $\beta$-adrenergic blocking agents, calcium channel blocking agents (dihydropyridines), phosphodiesterase inhibitors, thiazide diruetics. PCIP, Primary Care Information Project.

non-PCIP groups) participating in this incentive program were excluded from the analyses (Table 3 ), less improvement was observed for members with diabetes on diabetes-specific medications (OR, 1.76; 95\% CI, 0.96-3.24 for PCIP vs OR, 1.12; 95\% CI 0.80-1.58 for non-PCIP).

\section{Discussion}

Provider participation in the PCIP was associated with greater improvements in the proportion of adherent members between 2 time points for some groups, such as members with diabetes taking diabetes-specific and lipid-controlling medications. However, these associations were generally nonsignificant, and the magnitude and significance of the improvements were diminished when practices participating in a program providing reduced prescription co-pays to members with chronic conditions were excluded from the analyses. These results suggest that reduced costs for the patient may have been a stronger factor in increasing medication adherence, which is similar to observations by other researchers. ${ }^{24-26}$ Both groups showed improvements among members with hypertension or diabetes taking hypertension-specific drugs, with the non-PCIP group showing greater improvement.

Though the PCIP has facilitated quality improvement and promoted population health by educating providers on quality improvement and 
Table 3. Logistic Regression Models Adjusting for Age, Sex, and Primary Care Provider Participation in the Primary Care Information Project

\begin{tabular}{|c|c|c|c|c|}
\hline & \multicolumn{2}{|c|}{ All } & \multicolumn{2}{|c|}{$\begin{array}{c}\text { PCMH Pilot } \\
\text { Practices Removed }\end{array}$} \\
\hline & $\mathrm{OR} *$ & $95 \% \mathrm{CI}$ & $\mathrm{OR}^{*}$ & $95 \% \mathrm{CI}$ \\
\hline \multicolumn{5}{|l|}{ Diabetes (only) } \\
\hline \multicolumn{5}{|c|}{ Diabetes-specific medications $\dagger$} \\
\hline Non-PCIP & 1.14 & $0.81-1.60$ & 1.12 & $0.79-1.58$ \\
\hline PCIP & $2.03 \neq$ & $1.08-3.83$ & 1.76 & $0.96-3.24$ \\
\hline \multicolumn{5}{|c|}{ Lipid-controlling medications $\$$} \\
\hline Non-PCIP & 0.85 & $0.55-1.32$ & 0.83 & $0.53-1.29$ \\
\hline PCIP & 1.64 & $0.73-3.65$ & 1.59 & $0.73-3.44$ \\
\hline \multicolumn{5}{|c|}{ Hypertension (only) } \\
\hline \multicolumn{5}{|c|}{ Hypertension-specific medications\| } \\
\hline Non-PCIP & $1.26 \neq$ & $1.15-1.38$ & $1.26 \neq$ & $1.15-1.38$ \\
\hline PCIP & $1.24 \ddagger$ & $1.03-1.49$ & $1.24 \neq$ & $1.03-1.48$ \\
\hline \multicolumn{5}{|c|}{ Lipid-controlling medications $\$$} \\
\hline Non-PCIP & $1.28 \neq$ & $1.13-1.44$ & $1.28 \neq$ & $1.13-1.49$ \\
\hline PCIP & 1.11 & $0.86-1.44$ & 1.16 & $0.90-1.50$ \\
\hline \multicolumn{5}{|c|}{ Comorbid diabetes and hypertension } \\
\hline \multicolumn{5}{|c|}{ Diabetes-specific medications $\dagger$} \\
\hline Non-PCIP & 1.03 & $0.90-1.18$ & 1.05 & $0.92-1.21$ \\
\hline PCIP & 1.06 & $0.81-1.40$ & 1.14 & $0.88-1.49$ \\
\hline \multicolumn{5}{|c|}{ Hypertension-specific medications\| } \\
\hline Non-PCIP & $1.19 \neq$ & $1.04-1.36$ & $1.19 \neq$ & $1.04-1.36$ \\
\hline PCIP & 1.10 & $0.84-1.44$ & 1.10 & $0.85-1.43$ \\
\hline \multicolumn{5}{|c|}{ Lipid-controlling medications $\S$} \\
\hline Non-PCIP & 1.14 & $0.99-1.32$ & 1.16 & $1.00-1.33$ \\
\hline PCIP & 1.26 & $0.93-1.72$ & 1.25 & $0.94-1.68$ \\
\hline
\end{tabular}

${ }^{*}$ Odd ratios $(\mathrm{OR})$ shown for changes in the odds of the proportion of members who are adherent (i.e., medication possession ratio $\geq 80 \%$ ) from baseline to the end of the study.

†Diabetes therapeutic drug classes include biguanides, sulfonylureas, thiazolidinediones, insulins, dipeptidyl peptidase IV inhibitors. $\ddagger P$ values $<.05$.

\$Lipid-controlling therapeutic drug classes include HMG-CoA reductase inhibitors and fibric acid derivatives.

$\|$ Hypertension therapeutic drug classes include angiotensin-converting enzyme inhibitors, angiotensin II receptor antagonists, beta-adrenergic blocking agents, calcium channel blocking agents (dihydropyridines), phosphodiesterase inhibitors, thiazide diruetics. CI, confidence interval; PCMH, patient-centered medical home; OR, odds ratio; PCIP, Primary Care Information Project.

helping them to redesign workflows to use their EHRs more effectively at the point of care, these general activities alone may not be strongly associated with increasing the MPR. Improving medication adherence is a complex issue that requires further research and evaluation. In addition to lowering patient costs, models in which improved medication adherence has been observed include use of automated calling systems to conduct patient outreach $^{34,35}$ and use of pharmacy personnel to counsel patients on their medications as part of the team-based approach within the PCMH setting. ${ }^{36-39}$

There are several limitations of this study. Using health claims data, we were not able to assess whether the individual actually took the medication or whether their blood pressure, glucose, or cholesterol were under control. While the non-PCIP providers had a higher proportion of members with hypertension compared with the PCIP providers, this would not have affected our results because our analysis was conducted at the patient level. In addition, while the PCIP has assisted many practices in New York City with adoption and use of health information technology, we do not know the extent of adoption or assistance received by providers that were not participating in PCIP programs, and we cannot draw direct conclusions about the use or impact of health information technology or technical assistance. 
A number of barriers to medication adherence have been noted in the literature, including age, costs of medications, polypharmacy, pill burden, dosing frequency, adverse effects and tolerability, patient knowledge and understanding of disease, and physician-patient communication. ${ }^{40-43}$ Health information systems have the potential to be used to facilitate the assessment of patient adherence to medication regimens by developing and using tools within the EHR to (1) increase opportunities for patient education and patient-provider communication about medication adherence and (2) promote the utilization of techniques for improving medication adherence to multiple-pill regimens, such as recommending combination pills, use of pill sorters, and once-a-day dosing. As observed in this study, reducing patient prescription cost is another method to improve patient prescription fill rates.

Each primary care visit is an opportunity to educate and engage patients in improving their health. Health information systems and practice support in the primary care setting, coupled with patient incentives, can significantly improve patient quality of care and potentially improve patient engagement in managing their chronic conditions beyond the office visit.

\section{References}

1. National Center for Chronic Disease Prevention and Health Promotion, Centers for Disease Control and Prevention. The burden of chronic diseases and their risk factors: national and state perspectives. Atlanta: CDC; 2002.

2. Eckel RH, Kahn R, Robertson RM, Rizza RA. Preventing cardiovascular disease and diabetes: a call to action from the American Diabetes Association and the American Heart Association. Circulation 2006; 113:2943-6.

3. Mensah GA, Brown DW. An overview of cardiovascular disease burden in the United States. Health Aff (Millwood) 2007;26:38-48.

4. Cutler JA, Sorlie PD, Wolz M, Thom T, Fields LE, Roccella EJ. Trends in hypertension prevalence, awareness, treatment, and control rates in United States adults between 1988-1994 and 1999-2004. Hypertension 2008;52:818-27.

5. Ostbye T, Yarnall KS, Krause KM, Pollak KI, Gradison M, Michener JL. Is there time for management of patients with chronic diseases in primary care? Ann Fam Med 2005;3:209-14.

6. Bodenheimer T, Chen E, Bennett HD. Confronting the growing burden of chronic disease: can the U.S. health care workforce do the job? Health Aff (Millwood) 2009;28:64-74.
7. Thier SL, Yu-Isenberg KS, Leas BF, et al. In chronic disease, nationwide data show poor adherence by patients to medication and by physicians to guidelines. Manag Care 2008;17:48-52.

8. Briesacher BA, Andrade SE, Fouayzi H, Chan KA. Comparison of drug adherence rates among patients with seven different medical conditions. Pharmacotherapy 2008;28:437-43.

9. Yeaw J, Benner JS, Walt JG, Sian S, Smith DB. Comparing adherence and persistence across 6 chronic medication classes. J Manag Care Pharm 2009; 15:728-40.

10. Kyanko KA, Franklin RH, Angell SY. Adherence to chronic disease medications among New York City Medicaid participants. J Urban Health 2013;90: 323-8.

11. Pladevall M, Williams LK, Potts LA, Divine G, Xi $\mathrm{H}$, Lafata JE. Clinical outcomes and adherence to medications measured by claims data in patients with diabetes. Diabetes Care 2004;27:2800-5.

12. Parris ES, Lawrence DB, Mohn LA, Long LB. Adherence to statin therapy and LDL cholesterol goal attainment by patients with diabetes and dyslipidemia. Diabetes Care 2005;28:595-9.

13. Svarstad BL, Shireman TI, Sweeney JK. Using drug claims data to assess the relationship of medication adherence with hospitalization and costs. Psychiatr Serv 2001;52:805-11.

14. Lau DT, Nau DP. Oral antihyperglycemic medication nonadherence and subsequent hospitalization among individuals with type 2 diabetes. Diabetes Care 2004;27:2149-53.

15. Ho PM, Spertus JA, Masoudi FA, et al. Impact of medication therapy discontinuation on mortality after myocardial infarction. Arch Intern Med 2006; 166:1842-7.

16. Newby LK, LaPointe NM, Chen AY, et al. Longterm adherence to evidence-based secondary prevention therapies in coronary artery disease. Circulation 2006;113:203-12.

17. Ho PM, Rumsfeld JS, Masoudi FA, et al. Effect of medication nonadherence on hospitalization and mortality among patients with diabetes mellitus. Arch Intern Med 2006;166:1836-41.

18. Balkrishnan R, Rajagopalan R, Camacho FT, Huston SA, Murray FT, Anderson RT. Predictors of medication adherence and associated health care costs in an older population with type 2 diabetes mellitus: a longitudinal cohort study. Clin Ther 2003;25:2958-71.

19. Sokol MC, McGuigan KA, Verbrugge RR, Epstein RS. Impact of medication adherence on hospitalization risk and healthcare cost. Med Care 2005;43: 521-30.

20. Roebuck MC, Liberman JN, Gemmill-Toyama M, Brennan TA. Medication adherence leads to lower health care use and costs despite increased drug spending. Health Aff (Millwood) 2011;30:91-9. 
21. Friedberg MW, Lai DJ, Hussey PS, Schneider EC. A guide to the medical home as a practicelevel intervention. Am J Manag Care 2009;15: S291-9.

22. Carter BL, Bosworth HB, Green BB. The hypertension team: the role of the pharmacist, nurse, and teamwork in hypertension therapy. J Clin Hypertens (Greenwich) 2012;14:51-65.

23. Kraschnewski JL, Gabbay RA. Role of health information technologies in the Patient-centered Medical Home. J Diabetes Sci Technol 2013;7:1376-85.

24. Shah NR, Hirsch AG, Zacker C, Taylor S, Wood GC, Stewart WF. Factors associated with first-fill adherence rates for diabetic medications: a cohort study. J Gen Intern Med 2009;24:233-7.

25. Hunt J, Rozenfeld Y, Shenolikar R. Effect of patient medication cost share on adherence and glycemic control. Manag Care 2009;18:47-53.

26. Gibson TB, Wang S, Kelly E, et al. A value-based insurance design program at a large company boosted medication adherence for employees with chronic illnesses. Health Aff (Millwood) 2011;30: 109-17.

27. Mostashari F, Tripathi M, Kendall M. A tale of two large community electronic health record extension projects. Health Aff (Millwood) 2009;28:345-56.

28. Farley TA, Dalal MA, Mostashari F, Frieden TR. Deaths preventable in the U.S. by improvements in use of clinical preventive services. Am J Manag Care 2010;38:600-9.

29. Take care New York 2012: a policy for a healthier New York City, September 2009. New York: New York City Department of Health \& Mental Hygiene. Available from: http://www.nyc.gov/html/ doh/downloads/pdf/tcny/tcny-2012.pdf. Accessed May 5, 2015.

30. Ford ES, Giles WH, Dietz WH. Prevalence of the metabolic syndrome among US adults: findings from the third National Health and Nutrition Examination Survey. JAMA 2002;287:356-9.

31. Payscale, Inc. Average salary for Seiu 32BJ employees. Available from: http://www.payscale.com/research/ US/Employer=Seiu_32Bj/Salary. Accessed March $3,2015$.

32. 32BJ SEIU. Who we are. Available from: http:// www.seiu32bj.org/who-we-are/. Accessed March 3, 2015.
33. Andrade SE, Kahler KH, Frech F, Chan KA. Methods for evaluation of medication adherence and persistence using automated databases. Pharmacoepidemiol Drug Saf 2006;15:565-74, discussion 75-77.

34. Bender BG, Apter A, Bogen DK, et al. Test of an interactive voice response intervention to improve adherence to controller medications in adults with asthma. J Am Board Fam Med 2010;23:159-65.

35. Vollmer WM, Feldstein A, Smith DH, et al. Use of health information technology to improve medication adherence. Am J Manag Care 2011;17:SP7987.

36. Pape GA, Hunt JS, Butler KL, et al. Team-based care approach to cholesterol management in diabetes mellitus: two-year cluster randomized controlled trial. Arch Intern Med 2011;171:1480-6.

37. Allen JK, Dennison-Himmelfarb CR, Szanton SL, et al. Community Outreach and Cardiovascular Health $(\mathrm{COACH})$ Trial: a randomized, controlled trial of nurse practitioner/community health worker cardiovascular disease risk reduction in urban community health centers. Circ Cardiovasc Qual Outcomes 2011;4:595-602.

38. Berdine HJ, Skomo ML. Development and integration of pharmacist clinical services into the patientcentered medical home. J Am Pharm Assoc 2012;52: 661-7.

39. Odum L, Whaley-Connell A. The role of teambased care involving pharmacists to improve cardiovascular and renal outcomes. Cardiorenal Med 2012; 2:243-50.

40. Wroth TH, Pathman DE. Primary medication adherence in a rural population: the role of the patientphysician relationship and satisfaction with care. J Am Board Fam Med 2006;19:478-86.

41. Munger MA, Van Tassell BW, LaFleur J. Medication nonadherence: an unrecognized cardiovascular risk factor. MedGenMed 2007;9:58.

42. Kaplan JE, Keeley RD, Engel M, Emsermann C, Brody D. Aspects of patient and clinician language predict adherence to antidepressant medication. J Am Board Fam Med 2013;26:409-20.

43. Rashid MA, Edwards D, Walter FM, Mant J. Medication taking in coronary artery disease: a systematic review and qualitative synthesis. Ann Fam Med 2014;12:224-32. 